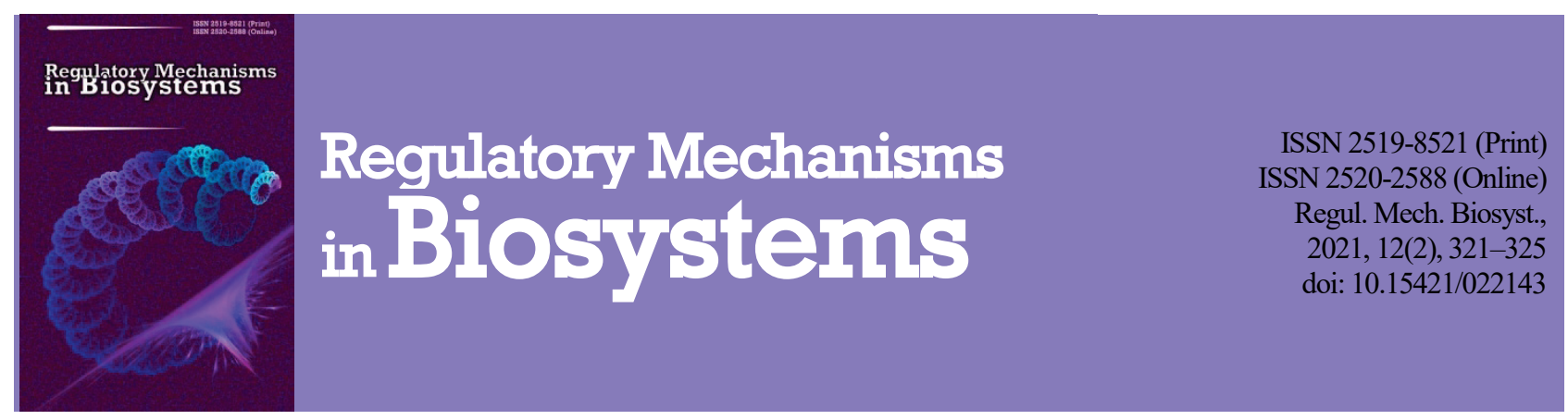

\title{
Influence of sugars on biofilm formation of Staphylococcus epidermidis
}

\author{
A. O. Vashchenko*, Y. S. Voronkova*, E. E. Kulyk*, O. S. Snisar*, O. I. Sidashenko**, O. S. Voronkova* \\ * Oles Honchar Dnipro National University, Dnipro, Ukraine \\ **Ukrainian State University of Chemical Technology, Dnipro, Ukraine
}

\section{Article info \\ Received 29.03.2021 \\ Received in revised form 24.04.2021 \\ Accepted 25.04.2021 \\ Oles Honchar Dnipro National University, D. Yavornitskii av., 35 , Dnipro, 49044, Ukraine Tel. +38-096-225-04-63. E-mail: \\ voronkova_olga@iua}

Ukrainian State University of Chemical Technology, Gagarin av., 8,

Dnipro, 49005, Ukraine Tel. +38-050-211-25-20. E-mail: microb.sidashenko @gmail.com

\author{
Vashchenko, A. O., Voronkova, Y. S., Kulyk, E. E., Snisar, O. S., Sidashenko, O. I., \& Voronkova, O. S. (2021). Influence of sugars \\ on biofilm formation of Staphylococcus epidermidis. Regulatory Mechanisms in Biosystems, 12(2), 321-325. doi:10.15421/022143
}

The problem of biofilm formation by clinical strains of opportunistic bacteria is one of the most significant for medicine, because in a state of biofilm bacteria become more resistant to environmental factors, including antibiotics, a situation that can cause failure of treatment. Among opportunistic pathogens staphylococci are of special interest. Knowledge about the peculiarities of biofilm formation of these strains, in particular the polysaccharide biosynthesis, can be used for creation of a strategy of prophylaxis of different lesions that bind with staphylococci. The effect of different concentrations of the most widespread sugars (glucose, sucrose, lactose, galactose) on the activity of biofilm formation by strains of Staphylococcus epidermidis was investigated. Strains of S. epidermidis $(\mathrm{n}=7)$ were isolated from the reproductive tract of women with dysbiosis. The cultures were grown in universal synthetic media with concentration of one of the listed sugars ( $0.5-3.0 \%$ ) during $72 \mathrm{~h}$. Results were obtained colorimetrically. We studied the number of cells in biofilm and the index of biofilm formation. The largest number of cells in the biofilm was observed when the culture incubated in a medium with $2.0 \%$ of glucose (increase of 25.3 times compared to control). The amount of CFU in the control biofilm was $9.96 \mathrm{lg} \mathrm{CFU} / \mathrm{mL}$. The glucose concentration of $3.0 \%$ inhibited the biofilm formation: the number of cells in the biofilm was 569 times less compared to the control. The highest value of biofilm formation index was 7.2, which was 1.3 times higher than the control (5.4). In the presence of lactose and galactose in nutrient medium in concentrations from $1.0 \%$ a decrease in the number of cells and biofilm formation index were observed. The received data show that process of biofilm formation is significantly dependent on external sources of sugars, which can indicate the possibility of their use as antibiofilm drug compounds, which inhibit membrane transport of sugars in bacteria.

Keywords: staphylococci; biofilm growth; glucose; sucrose; lactose; galactose; dysbiosis.

\section{Introduction}

Nowadays the problem of staphylococcal biofilms is positioned as one of the most important in medical practice. In the first place, this is usually due to the fact that in the form of film microorganisms acquire both an enhancement of their inherent qualities and new features, especially when it includes to polymicrobial communities (Bester et al., 2010; Sobkova et al., 2017). However, the study of biofilms originates in studies of marine and oceanic microbial communities, where microorganisms are often found in an attached state both in natural habitats and in water-related industrial facilities (Costerton et al., 1987; Paharik \& Horswill, 2016). Only relatively recently was it found that the development of biofilms is important for many types of infections and currently biofilm formation is a typical way of bacterial persistence in macroorganisms (Jacqueline \& Caillon, 2014; Lavryk \& Kornijchuk, 2015; Schilcher \& Horswill, 2020). Therefore, today the predominant direction of research is biofilms related to infectious processes. According to the National Institutes of Health (USA), up to $80 \%$ of human infections are associated with biofilm formation (Sun et al., 2013). Such pathological processes are a serious clinical problem, because in the biofilm form microorganisms increase their resistance to environmental factors such as antibiotics, antiseptics and disinfectants, pH, radiation etc. (Høiby et al., 2009; McKew et al., 2011; Sobkova et al., 2017; Palchykov et al., 2019; Zazharskyi et al., 2019a, 2019b).

Among the great variety of human pathological processes, infections caused by staphylococci occupy a special place. Bacteria of the genus Staphylococcus include a diverse group of commensals that colonize the skin and mucous membranes of mammals, including humans (Kuchtyn et al., 2013; Sobkova et al., 2017). Some of the most well-known mem- bers of this genus, such as $S$. aureus and S. epidermidis, are also opportunistic pathogens, which are associated with a huge burden on the health care system (Becker et al., 2014; Paharik \& Horswill, 2016). In particular, statistics in the USA show that $S$. aureus and coagulase-negative staphylococci rank first and third among the most common etiological agents of nosocomial infections, respectively, including infections associated with medical equipment and surgical wounds (Weiner et al., 2016).

One of the reasons for the "problematic" nature of staphylococci is their ability to attach to surfaces and develop into complex structures known as biofilms (Kiedrowski \& Horswill, 2011; Rupp, 2014). The structure and properties of biofilms have been studied for a long time and a considerable amount of information has already been accumulated. However, issues related to purely practical interests, such as the search for tools and schemes to treat lesions caused by biofilms, remain open (Buzon-Duran et al., 2017). To address such issues, it is necessary to have knowledge about the peculiarities of the biofilm response to external factors and their combinations, and knowledge is needed not only about the structure of biofilms, but also about their physiological and biochemical features (Schilcher \& Horswill, 2020). And it is here that the existing scientific achievements are much smaller (Bester et al., 2010; Hou et al., 2012). In particular, the question of metabolic properties of biofilms is insufficiently studied, there is almost no generalized information about the influence of factors of different nature on the formed biofilm, and only some aspects of their effect on biofilm strains are studied (Sousa et al., 2006; Kroukampand \& Wolfaardt, 2009).

Among the significant amount of data on the modeling of biofilms, there are only some materials on biofilms associated with the microbiota of open cavities of humans and animals (Coenye \& Nelis, 2010; Lebeaux et al., 2013). This, in particular, applies to the simulation of disorders of the 
genital tract microbiota, although it is known that the biofilm organization in this habitat presents the main threat of chronicity of such pathological processes as bacterial vaginosis, because it delays transient microorganisms and increases their survival under antagonism and environmental factors (Brotman et al., 2008; Patterson et al., 2010; Lavryk \& Kornijchuk, 2015; Sobkova et al., 2017). Of particular interest is the study of staphylococcal biofilms, which are among the most common, especially given the ability of staphylococci to colonize almost any habitat of the human body and for a long time, and sometimes for life, persist in the body, causing recurrence of infections (Diemond-Hernandez, 2010; Hou et al., 2012; Sobkova et al., 2017).

Formation of biofilm is not an obligatory condition for the living of microorganisms, however, this form significantly increases the survival of microorganisms in the environment (Høiby et al., 2010; McKew et al., 2011; Sun et al., 2013), which is related to the structure of the biofilm, in particular, with the presence of the matrix layer around the cell cluster.

Study of the effect of sugars on the formation of biofilms is of significant interest, since the effect of the formation of the exopolymeric matrix depends on the sugars. It is typical for staphylococci (Vergara-Irigaray et al., 2008), preferably containing polysaccharides. Monomers for the synthesis of these polysaccharides are external sugars, which can be diluted after absorption by staphylococci as a source of energy and as a plastic material (Becker et al., 2014).

The aim of the research was to investigate the effect of different concentrations of the most widespread sugars (glucose, sucrose, lactose, galactose) on the activity of biofilm formation by strains of $S$. epidermidis.

\section{Materials and methods}

For the research 96-well immunological plastic plates (LAB-Medica, China) were used. The number of viable cells and the biofilm-formation index of $S$. epidermidis strains $(n=7)$ isolated from the reproductive tract of women with dysbiosis were determined. In each well of the vertical rows of the plate $200 \mu \mathrm{L}$ of a universal synthetic medium was applied (g/L: citric acid - 10, asparagine - $3, \mathrm{~K}_{2} \mathrm{HPO}_{4}-6, \mathrm{ZnSO}_{4}-0.5, \mathrm{MgSO}_{4}-$ $0.7, \mathrm{FeSO}_{4}-0.1, \mathrm{NaCl}-6, \mathrm{Na}_{2} \mathrm{HPO}_{4}-1.5$, glycine -1.0 , amber acid 3.0 and glycerin $-40-50 \mathrm{~mL}$. Distilled water was added to 1 liter. The $\mathrm{pH}$ of the medium for growing staphylococci was set as 7.5-7.6 (Evglevsky et al., 2011) with different concentrations of sugars: glucose, sucrose, lactose and galactose (Table 1).

\section{Table 1}

Preparation of medium with different concentrations of sugars (glucose, or sucrose, or lactose, or galactose)

\begin{tabular}{cc}
\hline Base medium, $\mathrm{mL}$ & Concentration of sugar, $\%$ \\
\hline 99.5 & 0.5 \\
99.0 & 1.0 \\
98.5 & 1.5 \\
98.0 & 2.0 \\
97.5 & 2.5 \\
97.0 & 3.0 \\
\hline
\end{tabular}

In a nutrient medium $100 \mu \mathrm{L}$ of a bacterial suspension containing $1.0 \times 10^{4} \mathrm{CFU} / \mathrm{mL}$ was placed. As a control a well with $200 \mu \mathrm{L}$ of sterile base medium and $100 \mu \mathrm{L}$ of bacterial suspension containing $1.0 \times 10^{4}$ $\mathrm{CFU} / \mathrm{mL}$ was used: it was a control of biofilm-formation. Another control was a well with $200 \mu \mathrm{L}$ of sterile base of the medium and $100 \mu \mathrm{L}$ of isotonic solution $(0.5 \% \mathrm{NaCl})$ : it was a control of the nutrient medium.

Preparation of suspensions of microorganisms with a determined concentration of microbial cells was made in a sterile isotonic solution $(0.5 \% \mathrm{NaCl})$ and with the next inoculation of dilutions prepared from the obtained bacterial suspension to determine the amount of CFU $/ \mathrm{mL}$.

The analysis of film growth was made $72 \mathrm{~h}$ after inoculation of the cell suspension into the wells of the plate.

To determine the number of viable cells in the formed biofilm the residues of the nutrient medium were removed by micropipette from the wells of the plate, and then the biofilm was washed twice with isotonic solution $(0.5 \% \mathrm{NaCl})$. The biofilm was homogenized. From the obtained bacterial suspension, the 10-fold dilution were made and inoculated on Petri dishes with meat-peptonic broth. After $24 \mathrm{~h}$ of incubation, the num- ber of CFU $/ \mathrm{mL}$ was calculated. The index of biofilm formation was determined by measuring of the amount of crystalline violet associated dye on a photo-electro-colorimeter of KFK-2MP. After the cultivation, the residue of the nutrient medium was removed by a micropipette. The surface of the biofilm was washed with $0.01 \mathrm{M}$ phosphate buffer $(\mathrm{pH}=7.2)$ and stained with $0.1 \%$ crystalline violet for $10 \mathrm{~min}$.

The surface of the biofilm was washed with isotonic solution $(0.5 \%$ $\mathrm{NaCl}$ ) and dried at room temperature, then the dye bound to the biofilm was extracted with ethanol (Stepanovic et al., 2000). Then, the measurements of the optical density of ethanol extracts on a photo-electrocolorimeter at a wavelength of $590 \mathrm{~nm}$ in a cuvette with an optical path length of $1 \mathrm{~cm}$ were made. The growth of the biofilm of the studied strains under the influence of various concentrations of sugars was evaluated by the presence of a difference in optical density between the experimental and control samples, followed by the calculation of the biofilm formation index as relation of a result of multiplication of optical density values of crystalline violet and planktonic cells to optical density values of inoculating dose. Wavelength $590 \mathrm{~nm}$ was used (Santos \& Soviero, 2007). Results were calculated in conventional units.

All experiments were performed in triplicate for three independent cultures and the means \pm standard error $(\mathrm{x} \pm \mathrm{SE})$ were calculated.

\section{Results}

After 72 hours of incubation, we counted the number of cells in biofilms of $S$. epidermidis, which were formed in media at different concentrations of sugars (Fig. 1).

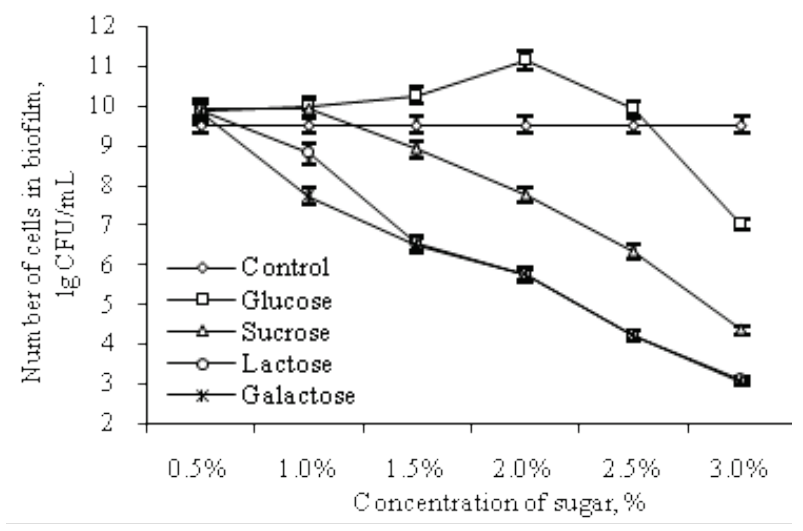

Fig. 1. Dynamics of the number of colony-forming units in S. epidermidis biofilms after $72 \mathrm{~h}$ cultivation in single sugar medium $(\mathrm{x} \pm \mathrm{SE}, \mathrm{n}=3)$

The largest number of cells in the biofilm was observed for the culture incubated in a medium with $2.0 \%$ of glucose, which exceeded 25.3 times the number of cells in the control well. The amount of CFU in the control biofilm was $9.96 \mathrm{lg}$ CFU $/ \mathrm{mL}$. The glucose concentration of $1.5 \%$ also resulted in a 2.0-fold increase of the number of cells in the biofilm compared to the control. When the glucose content in the nutrient medium was $3.0 \%$, inhibition of biofilm formation was noted, as the number of biofilm cells formed at this concentration was 569 times less compared to the control. Glucose concentrations $0.5-1.0 \%$ did not cause significant changes in the number of cells in the biofilm compared to the control.

During the cultivation of S. epidermidis biofilms in media containing different concentrations of other studied sugars - sucrose, lactose and galactose, there was a decrease in the amount of cells in the biofilm depending on the increase in sugar concentration. The sucrose content 0.5 $1.0 \%$ did not have a significant effect on the number of cells in the biofilm: the values were almost consistent with the control. But the increase in the concentration of sucrose in the nutrient medium to $1.5 \%$ caused a decrease of the number of cells in the biofilm of $S$. epidermidis by 11 times compared with the control. A further increase in the sucrose content in the culture medium led to a gradual decrease in the number of biofilm cells: at $2.0 \%-170$ times, at $2.5 \%-4.6 \times 10^{3}$ times, at $3.0 \%-$ $2.0 \times 10^{5}$ times compared to control. If lactose content was $0.5 \%$ in the medium, no significant changes in cell count compared to the control 
indicator were observed. The gradual increase in the concentration of this sugar provoked a decrease in the content of cells in the biofilm compared to the control. Thus, during the formation of the biofilm in a medium containing $1.0 \%$ lactose, there was a decrease in the number of cells by 7.8 times, $1.5 \%$ lactose $-2.3 \times 10^{3}$ times, $2.0 \%-2.0 \times 10^{4}$ times, $2.5 \%-$ $4.2 \times 10^{5}$ times, $3.0 \%$ lactose $-6.1 \times 10^{6}$ times compared with the control. A similar effect on the biofilm formation was shown by galactose, as only sources of carbohydrates, with content of $0.5 \%$ the number of cells in the biofilm corresponded with the control amount. The subsequent increase of sugar concentration caused a decrease in the number of cells. During cultivation in a nutrient medium containing $1.0 \%$ galactose, there was a decrease in the number of CFU by 190 times, at a content of $1.5 \%-3.7 \times$ $10^{3}$ times, $2.0 \%$ galactose $-2.2 \times 10^{4}$ times, $2.5 \%-4.9 \times 10^{5}$ times, $3.0 \%$ galactose $-8.1 \times 10^{6}$ times compared with the control.

The effect of all sugars on biofilm formation index of $S$. epidermidis strains is represented in Figure 2.

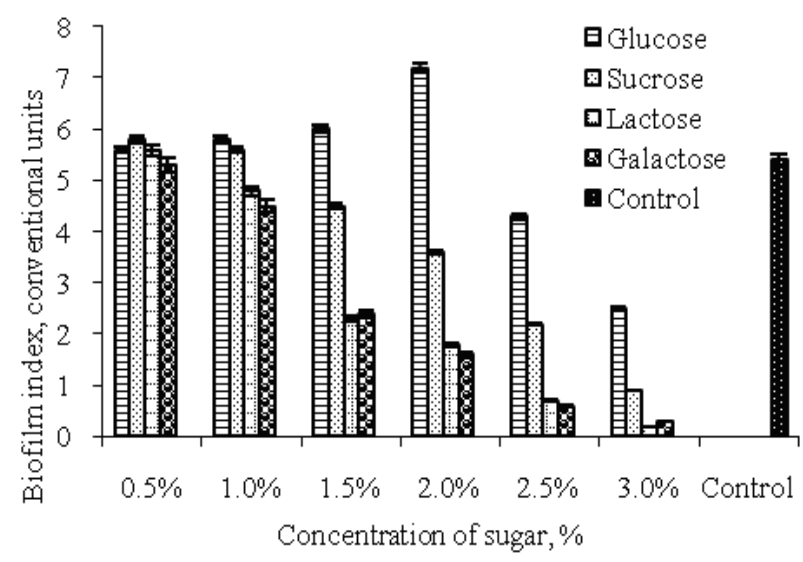

Fig. 2. Dynamics of biofilm formation index in S. epidermidis biofilms after $72 \mathrm{~h}$ cultivation in single sugar medium $(\mathrm{x} \pm \mathrm{SE}, \mathrm{n}=3)$

The formation of the S. epidermidis biofilm occurred during the addition of all studied glucose concentrations. As in the case of the number of cells, the highest value of biofilm formation index was 7.2. It was observed during the cultivation of the biofilm in a medium containing $2.0 \%$ glucose: the value of biofilm formation index was 1.3 times higher than the control. During the formation of the biofilm of $S$. epidermidis in a nutrient medium containing $0.5-1.0 \%$ glucose the biofilm formation index was 5.6 and 5.8, respectively, significantly corresponding to the control value, which indicates a low level of dependence of the biofilm formation on these concentrations of sugar. The biofilm formation index of S. epidermidis strains, which were determined for biofilms formed in a medium containing $2.5 \%$ glucose, can also be compared with the control-5.4. As with the number of cells, a glucose content of $3.0 \%$ provoked a 2.2-fold decrease in the biofilm formation index compared to control. The biofilm formation index found for biofilms formed in a medium with $2.0 \%$ glucose was 2.9 times higher than the biofilm formation index for biofilms formed in a medium with $3.0 \%$ glucose.

It was found that the formation of the $S$. epidermidis biofilm was neutrally affected by the sucrose content of $0.5 \%$ to $1.0 \%$ in the medium, as biofilm formation index coincided with the control, which was 5.4, which confirms the results obtained when determining the number of cells. A further increase in the concentration of sucrose in the culture medium led to a decrease in the biofilm formation index. Thus, when studying the effect of sucrose concentration of $1.5 \%$ on the formation of S. epidermidis biofilm, we noted a decrease in the biofilm formation index by 1.2 times compared with the control, sucrose content of $2.0 \%$ led to a further decrease in the biofilm formation index -2.5 times, and sucrose content of $3.0 \%$ led to a decrease in the biofilm formation index by 6.0 times. It was found that during the increase of lactose concentration $1.0-3.0 \%$ there was a decrease in the intensity of biofilm formation. The biofilm formed most intensively if the concentration of lactose was $0.5 \%$, as biofilm formation index was 5.6, which may be coincided with the control data. At a content of $3.0 \%$ lactose in the nutrient medium, the biofilm formation index decreased 27.0 times compared with the control. The results obtained coin- cide with the data obtained during the determination of the number of biofilm cells.

With increase of galactose concentration, as in the case of lactose, there was a decrease in the intensity of biofilm formation. During the formation of the biofilm in the culture medium containing $0.5 \%$ galactose, the biofilm formation index coincided with the control index, with a further increase there was a decrease in the biofilm formation index. Thus, during the formation of the biofilm in a medium containing 3.0\% galactose the biofilm formation index was 18.0 times lower compared to the control, which was 5.4. Thus, we can conclude that the formation of the biofilm was more intense in the case of the addition of $2.0 \%$ glucose into the nutrient medium, as the number of cells increased by 25.3 times compared to the control, and the biofilm formation index was 7.2 , which is 1.3 times higher than the control index.

\section{Discussion}

Comparing the effect of sugars on the formation of biofilms by strains of S. aureus (Voronkova \& Shevchenko, 2017) and S. epidermidis, the following can be noted: the general features of the effect of sugars on strains of both species were a pronounced inhibitory effect at concentrations of $2.5 \%$ or more, and an almost neutral reaction at concentration of $0.5 \%$. In experimental research (Liu et al., 2020) it was shown that at concentration of glucose $0.5 \%$ with presence of $3.0 \% \mathrm{NaCl}$ in trypticase soy broth medium for different $S$. aureus strains variable capacities to form biofilms were observed, which indicates the role of genetic background in biofilm formation. However, there is a tendency to increase in biofilm formation. Also there is data showing that supplementing skim milk with $0.25 \%$ glucose significantly increased the production of biofilm by $S$. aureus strains, but this effect was only observed in slime-producing strains (Fabres-Klein et al., 2015). Also it was shown that addition of $0.25 \%$ glucose or fructose in a medium can provoke biofilm formation of S. epidermidis strains which didn't form biofilm on basic tryptone, a sugar free nutrient medium (Dobinski et al., 2003). In addition, for both types of staphylococci the greatest stimulating activity of glucose in relation to biofilm formation was determined, which was not observed for sucrose, lactose and galactose. The strains differed in that the maximum effect for S. aureus was within the concentration of sugars $1.5 \%$, and for strains of S. epidermidis - within $2.0 \%$. Such discrepancies may indicate differences in the functional activity of the strains in the biofilm.

The results of these studies suggest that the nutrient components of the meat-peptonic broth fully meet the needs of the system of biosynthesis of carbohydrate components of the $S$. epidermidis biofilm. The obtained data can be explained by the functioning of mechanisms close to the catabolic repression of biofilm formation in staphylococcal biofilms, which was found in bacteria of some species of the Enterobacteriaceae family (Korobov et al., 2010). In some research there is evidence showing that sources of carbon can determine the shape of S. epidermidis biofilm, and intensivity of growth depends on concentration of sugars, temperature and time of incubation: the biofilm showed a compact multilayered-shaped structure under both glucose and sucrose conditions, but there was a pile of organized cells in a condensed ball-shaped structure under the lactose (Zou \& Liu, 2020).

The study of the influence of sugars on the formation of biofilms is of particular interest, because the efficiency of formation of the exopolymer matrix depends on sugars, which in staphylococci as is known mainly contains polysaccharides (Arciola et al., 2015). The monomers for the construction of these polysaccharides are external sugars, which can be used by staphylococcal cells as an energy source and as a plastic material. The study of the influence of carbon sources on the formation of biofilms showed that the type of sugar and its concentration can have both positive and neutral or negative effects on the growth characteristics of staphylococcal biofilms. Thus, a neutral effect occurred when using the lowest of the studied concentrations of $0.5 \%$ of any of the four studied sugars glucose, sucrose, lactose or galactose, which is confirmed in the work of individual researchers (Korobov et al., 2010). Now the impact of the catabolite control protein $\mathrm{A}$ on carbon metabolism, up-regulation of certain virulence determinants, and resistance to cell wall-directed antibiotics is known and it has been shown that activity of this protein is activated in the 
presence of glucose or sucrose and can affect biofilm formation in Bacillus subtilis and Streptococcus mutans. The same effect was shown for S. aureus in the presence of glucose concentration in medium $1.0 \%$ (Seidl et al., 2008).

When we add any of these sugars into the nutrient medium at a concentration of $2.5 \%$ or more, a pronounced inhibitory effect on the formation of the biofilm was observed. There are indications that the only sugar required for biofilm formation is glucose, which is even used in modeling biofilm growth (O'Neill et al., 2007; Croes et al., 2009). We recorded a stimulatory effect when $1.5 \%$ glucose was added to the nutrient medium, which was accompanied by the largest increase in cell count and biofilm index compared to the control: the number of cells increased 7.76 times compared to the control biofilms grown on sugar-free medium. We should also note a slight stimulating effect of concentrations of $1.0 \%$ and $2.0 \%$ for cases of glucose and sucrose. These data suggest the results, obtained by Manandhar et al. (2018) that with addition of $1 \%$ glucose to trypticase soy broth medium the increase of biofilm formation was detected for more than $16 \%$ of species of coagulase negative staphylococci. Addition of sucrose (till 2\%) also increased biofilm detection including more than $30 \%$ of coagulase negative staphylococcal strains.

Lactose and galactose, starting from a concentration of $1.0 \%$, had a negative effect. In particular, the results obtained by us confirm those of other experiments (Korobov et al., 2010). At the same time, the presence of sugars in the culture medium will affect the formation of the biofilm matrix depending on the type of microorganisms. Thus, studies of staphylococcal strains have shown that the role of sucrose is not significant, while for Listeria monocytogenes its presence in the medium with Congo red is necessary for the development of biosynthetic exopolysaccharide strains (Ben Slama et al., 2012).

\section{Conclusion}

The stimulatory effect of addition of $2.0 \%$ glucose into the nutrient medium has been established, which resulted in a 25.3-fold increase in the number of cells and a 1.3-fold increase in the biofilm formation index compared with the control of the film grown on a sugar free medium. A slight stimulatory effect of glucose in concentrations of $1.5-2.0 \%$ was noted. The negative influence on the formation of biofilm of sucrose, lactose and galactose in concentrations of $1.0 \%$ and more was shown. The received data show that process of biofilm formation is significantly dependent on external sources of sugars, which can indicate possibility of their use as antibiofilm drug compounds, which inhibit membrane transport of sugars in bacteria.

\section{References}

Arciola, C. R., Campoccia, D., Ravaioli, S., \& Montanaro, L. (2015). Polysaccharide intercellular adhesin in biofilm: Structural and regulatory aspects. Frontiers in Cellular and Infection Microbiology, 5, 7.

Becker, K., Heilmann, C., \& Peters, G. (2014). Coagulase-negative staphylococci. Clinical Microbiology Review, 27, 870-926.

Ben Slama, R., Bekir, K., Miladi, H., Noumi, A., \& Bakhrouf, A. (2012). Adhesive ability and biofilm metabolic activity of Listeria monocytogenes strains before and after cold stress. African Journal of Biotechnology, 11(61), 12475-12482.

Bester, E., Kroukamp, O., Hausner, M., Edwards, E. A., \& Wolfaardt, G. M. (2010). Biofilm form and function: Carbon availability affects biofilm architecture, metabolic activity and planktonic cell yield. Journal of Applied Microbiology, 110, 387-398.

Brotman, R. M., Klebanoff, M. A., Nansel, T. R., Andrews, W. W., Schwebke, J. R., Zhang, J., Yu, K. F., Zenilman, J. M., \& Scharfstein, D. O. (2008). A longitudinal study of vaginal douching and bacterial vaginosis - a marginal structural modeling analysis. American Journal of Epidemiology, 168, 188-196.

Buzon-Duran, L., Alonso-Calleja, C., \& Riesco-Pelaez, F. (2017). Effect of sub-inhibitory concentrations of biocides on the architecture and viability of MRSA biofilms. Food Microbiology, 65, 294-301.

Coenye, T., \& Nelis, H. J. (2010). In vitro and in vivo model systems to study microbial biofilm formation. Joumal of Microbiological Methods, 83, 89-105.

Costerton, J. W., Cheng, K. J., Geesey, G. G., Ladd, T. I., Nickel, J. C., Dasgupta, M., \& Marrie, T. J. (1987). Bacterial biofilms in nature and disease. Annual Review of Microbiology, 41, 435-464.
Croes, S., Deurenberg, R. H., Boumans, M. L., Beisser, P. S., Neef, C., \& Stobberingh, E. E. (2009). Staphylococcus aureus biofilm formation at the physiologic glucose concentration depends on the S. aureus lineage. BMC Microbiology, 9, 229.

Diemond-Hernandez, B. (2010). Production of icaADBC encoded polysaccharide intercellular adhesin and therapeutic failure in pediatric patients with staphylococcal device-related infections. BMC Infectious Disease, 10, 68-74.

Dobinsky, S., Kiel, K., Rohde, H., Bartscht, K., Knobloch, J. K., Horstkotte, M. A., \& Mack, D. (2003). Glucose-related dissociation between icaADBC transcription and biofilm expression by Staphylococcus epidermidis: Evidence for an additional factor required for polysaccharide intercellular adhesin synthesis. Joumal of Bacteriology, 185(9), 2879-2886.

Evglevsky, D. A., Evlevsky, A. A., Semenyutin, V. V., Smimov, I. I., \& Tatarnikov, K. V. (2011). Universalnaya sinteticheskaya sreda dlya vyraschivaniya patogennyih i probioticheskih mikroorganizmov pri poluchenii biopreparatov [Universal synthetic nutrient medium for growing of pathogenic and probiotic microorganisms in the creation of biological preparation]. Vestnik Kurskoy Gosudarstvennoy Selskohozyaystvennoy Akademii, 4, 64-66 (in Russian).

Fabres-Klein, M. H., Caizer Santos, M. J., Contelli Klein, R., de Souza, G. N., \& de Oliveira Barros Ribon, A. (2015). An association between milk and slime increases biofilm production by bovine Staphylococcus aureus. BMC Veterinary Research, 11,3.

Høiby, N., Bjamsholt, T., Givskov, M., Molin, S., \& Ciofu, O. (2010). Antibiotic resistance of bacterial biofilms. International Journal of Antimicrobial Agents, 35, 322-332

Hou, W., Sun, X., Wang, Z., \& Zhang, Y. (2012). Biofilm-forming capacity of Staphylococcus epidermidis, Staphylococcus aureus, and Pseudomonas aeruginosa from ocular infections. Investigative Ophthalmology and Visual Science, 53(9), 5624-5631.

Jacqueline, C., \& Caillon, J. (2014). Impact of bacterial biofilm on the treatment of prosthetic joint infections. The Joumal of Antimicrobial Chemotherapy, 69(Suppl 1), i37-i40.

Kiedrowski, M. R., \& Horswill, A. R. (2011). New approaches for treating staphylococcal biofilm infections. Annals of the New York Academy of Sciences, 1241, 104-121.

Korobov, V. P., Lemkina, L. M., \& Monakhov, V. I. (2010). Analiz chuvstvitel'nosti processov formirovaniya bioplenok Staphylococcus epidermidis $33 \mathrm{k}$ nekotorym faktoram vneshnej sredy [Sensitivity assay for the processes of Staphylococcus epidermidis 33 biofilm formation with respect to several environmental factors]. Vestnik Permskogo Universiteta, Biologiya, 1(1), 59-63 (in Russian).

Kroukampand, O., \& Wolfaardt, G. M. (2009). $\mathrm{CO}_{2}$ production as an indicator of biofilm metabolism. Applied and Environmental Microbiology, 75(13), 4391-4397.

Kuchtyn, M. D., Perkiy, Y. B., \& Krushelnytska, N. V. (2013). Formuvannia zmishanykh bioplivok mikroorhanizmamy, yaki vydileni z doilnoho ustatkuvannia ta moloka syroho [Formation of mixed biofilms of microorganisms isolated from milking equipment and raw milk]. Veterynarna Medytsyna, 97, 442-443 (in Ukrainian).

Lagun, L. V., \& Zhavoronok, S. V. (2013). Bakterialnyye bioplenki i ikh rol' v razvitii infektsiy mochevyvodyashchikh putey [Bacterial biofilms and their role in urinary tract infections]. Meditsinskiy Zhurnal, 4, 21-27 (in Russian).

Lavryk, G., \& Kornijchuk, O. (2015). Bioplivkova forma stafilokokiv u mono- ta bivydovij kulturi v poiednanni z laktobatsylamy [Biofilm forms in mono- and mixed staphylococci species culture in combination with lactobacilli]. Studia Biologica, 9(3-4), 89-98 (in Ukrainian).

Lebeaux, D., Chauhan, A., Rendueles, O., \& Beloin, C. (2013). From in vitro to in vivo models of bacterial biofilm-related infections. Pathogens, 2, 288-356.

Liu, Y., Zhang, J., \& Ji, Y. (2020). Environmental factors modulate biofilm formation by Staphylococcus aureus. Science Progress, 103(1), 36850419898659.

Maianskii, A. N., \& Chebotar, I. V. (2011). Stafilokokkovye bioplenki: Struktura, regulyaciya, ottorzhenie [Staphylococcal biofilms: Structure, regulation, rejection]. Zhumal Mikrobiologii, Epidemiologii, i Immunobiologii, 1, 101-108 (in Russian).

Manandhar, S., Singh, A., Varma, A., Pandey, S., \& Shrivastava, N. (2018). Evaluation of methods to detect in vitro biofilm formation by staphylococcal clinical isolates. BMC Research Notes, 11, 714.

McKew, B. A., Taylor, J. D., McGenity, T. J., \& Underwood, G. J. C. (2011). Resistance and resilience of benthic biofilm communities from a temperate saltmarsh to desiccation and rewetting. ISME Journal, 5, 30-41.

O'Neill, E., Pozzi, C., Houston, P., Smyth, D., Humphreys, H., Robinson, D. A., \& O'Gara, J. P. (2007). Association between methicillin susceptibility and biofilm regulation in Staphylococcus aureus isolates from device-related infections. Joumal of Clinical Microbiology, 45(5), 1379-1388.

Paharik, A. E., \& Horswill, A. R. (2016). The staphylococcal biofilm: Adhesins, regulation, and host response. Microbiology Spectrum, 4(2), VMBF-00222015.

Palchykov, V. A., Zazharskyi, V. V., Brygadyrenko, V. V., Davydenko, P. O., Kulishenko, O. M., Borovik, I. V., Chumak, V., Kryvaya, A., \& Boyko, O. O. (2019). Bactericidal, protistocidal, nematodicidal properties and chemical com- 
position of ethanol extract of Punica granatum peel. Biosystems Diversity, 27(3), 300-306.

Patterson, J. L., Stull-Lane, A., Girerd, P. H., \& Jefferson, K. K. (2010). Analysis of adherence, biofilm formation and cytotoxicity suggests a greater virulence potential of Gardnerella vaginalis relative to other bacterial-vaginosis-associated anaerobes. Microbiology, 156(2), 392-399.

Rupp, M. E. (2014). Clinical characteristics of infections in humans due to Staphylococcus epidermidis. Methods in Molecular Biology, 1106, 1-16.

Santos, A. P., \& Soviero, V. M. (2007). Comparison between a simplified and a conventional biofilm index in relation to caries activity and gingivitis in the primary dentition. European Archives of Paediatric Dentistry, 8(4), 201-205.

Schilcher, K., \& Horswill, A. R. (2020). Staphylococcal biofilm development: Structure, regulation, and treatment strategies. Microbiology and Molecular Biology Reviews, 84(3), e00026-19.

Seidl, K., Goerke, C., Wolz, C., Mack, D., Berger-Bächi, B., \& Bischoff, M. (2008). Staphylococcus aureus $\mathrm{CcpA}$ affects biofilm formation. Infection and Immunity, 76(5), 2044-2050.

Sobkova, Z. V., Filonenko, H. V., Surmasheva, O. V., \& Rosada, M. O. (2017). Vyvchennia vydovoho skladu mikroorhanizmiv v bioplivkakh na sudynnykh ta sechovykh kateterakh u bahatoprofilnomu statsionari [Study of the species composition of microorganisms in biofilms on vascular and urinary catheters in a multiprofiled hospital]. Science Rise: Biological Science, 2(5), $38-42$ (in Ukrainian).

Sousa, C., Henriques, M., Azeredo, J., Teixeira, P., \& Oliveira, R. (2006). Metabolic activity of Staphylococcus epidermidis in biofilm versus planktonic cells. International Conference on BIOFILMS, Leipzig, Germany, 2006 - "BIOFILMS II: Attachment and detachment in pure and mixed cultures". P. 101.

Stepanovic, S., Vukovic, D., Dakic, I., Savic, B., \& Svabic-Vlahovic, M. (2000). A modified microtiter-plate test for quantification of staphylococcal biofilm formation. Joumal of Microbiological Methods, 40(2), 175-179.
Sun, F., Qu, F., Ling, Y., Mao, P., Xia, P., Chen, H., \& Zhou, D. (2013). Biofilmassociated infections: Antibiotic resistance and novel therapeutic strategies. Future Microbiology, 8(7), 877-886.

Vergara-Irigaray, M., Maira-Litrán, T., Merino, N., Pier, G. B., Penadés, J. R., \& Lasa, I. (2008). Wall teichoic acids are dispensable for anchoring the PNAG exopolysaccharide to the Staphylococcus aureus cell surface. Microbiology, 154(3), 865-877.

Voronkova, O. S., \& Shevchenko, T. M. (2017). Influence of different concentrations of sugars on the Staphylococcus aureus biofilm formation. Social Science and Humanity, 2, 29-36.

Weiner, L. M., Webb, A. K., Limbago, B., Dudeck, M. A., Patel, J., Kallen, A. J., Edwards, J. R., \& Sievert, D. M. (2016). Antimicrobial-resistant pathogens associated with healthcare-associated infections: Summary of data reported to the national healthcare safety network at the Centers for Disease Control and Prevention, 2011-2014. Infection Control and Hospital Epidemiology, 37(11), 1288-1301.

Zazharskyi, V. V., Davydenko, P. O., Kulishenko, O. M., Borovik, I. V., \& Brygadyrenko, V. V. (2019a). Antimicrobial activity of 50 plant extracts. Biosystems Diversity, 27(2), 163-169.

Zazharskyi, V., Davydenko, P., Kulishenko, O., Borovik, I., Brygadyrenko, V., \& Zazharska, N. (2019b). Antibacterial activity of herbal infusions against Staphylococcus aureus, Staphylococcus epidermidis and Pseudomonas aeruginosa in vitro. Magyar Állatorvosok Lapja, 141, 693-704.

Zou, M., \& Liu, D. (2020). Effects of carbon sources and temperature on the formation and structural characteristics of food-related Staphylococcus epidermidis biofilms. Food Science and Human Wellness, 9(4), 370-376. 